\title{
Correlation of humidity and temperature in conference rooms - preliminary tests
}

\author{
Katarzyna Gładyszewska-Fiedoruk ${ }^{1^{*}}$ \\ ${ }^{1}$ Bialystok University of Technology, Department of HVAC Engineering, 15-351 Białystok, Poland
}

\begin{abstract}
In three different conference rooms, temperature and humidity were measured, and then the correlation of these measured parameters was determined. The analysed rooms are located in buildings of the same construction and in the same town, in the temperate climate zone. The rooms had a different number of people. The experiment caused more questions than answers. The only concrete conclusions that can be formulated are that in two rooms the humidity was far too low. The HVAC system slightly disturbs the correlation of temperature and humidity. The density of people in the room affects the increase of humidity. Despite the use of air temperature controllers in all the analysed conference rooms, the temperature during the tests increased, mostly in the room with the largest number of people. The influence of the number of people on the correlation between the measured parameters has not been determined. It is also not specified if external conditions influence this correlation. Humidity measurements should be continued in rooms where there are a lot of people in various aspects. Above all, there must be constructed the mechanisms to control it.
\end{abstract}

\section{Introduction}

The humidity and air temperature are the main parameters of the IAQ. Also, they are the main parameters of comfort, so it is important to understand the mechanisms associated with these parameters [1-7].

The importance of research into humidity in the room has been noticed by Vellei et al. [8]. They made real measurements and developed a calculation scheme for designers, which considers the humidity with respect to thermal comfort. Measurements in residential buildings in New York were performed by Quinn and Shaman [9], in Poland by Krawczyk [2] and in classrooms by Nejat et al. [3]. They noticed that the presence of the heating system had no significant connection with higher or lower humidity. Appropriate humidity in rooms, especially in rooms where a large number of people are staying at the same time, is important due to the development of microorganisms and ways of their spread [9-12].

Relations between humidity and temperature have been known for centuries. Humidity is the ratio of the partial pressure of water vapor contained in the air, expressed as a percentage, to the vapor pressure of water saturated over a flat surface of clean water at

${ }^{*}$ Corresponding author: k.gladyszewska@pb.edu.pl 
the same temperature. Whereas, the vapor pressure is the partial pressure exerted by the water vapor in the air $[13,14]$.

The influence of humidity on humans is described in publications [1, 4, 9, 15-18]. Unfortunately, the simulation tests presented by $[1,15,17]$ were carried out in a climate chamber. These studies did not include real conditions in their scope of research.

Conference rooms are not an ideal research facility. People preoccupied with presentations do not want to cooperate in other studies. They do not want to fill in the questionnaires. They go to the deliberations, leave the meeting, have discussions with each other, ignore the requests, and are busy with their thoughts. It is not their bad will, but their commitment to the theme of the conference. Therefore, no entries related to IAQ studies in the conference rooms were found in the literature. The exception are publications [19, 20], in which the authors simulated the spread of viruses in the conference room. The participants of the conference were not needed to perform the presented research.

Standards and guidelines determine the optimal humidity in rooms at $40-60 \%$ in all countries, regardless of the climate zone [21-23]. They do not, however, indicate a method of control or a method of supervision in order to comply with them. The best standards will not change anything unless there are regulations regarding their compliance.

All of presented research are an attempt to determine changes in humidity in conference rooms and its correlation with temperature. In the conference rooms where temperature and humidity measurements were carried out, there were no conditions for conducting surveys for a better analysis of thermal comfort.

\section{Method and measurements}

The research was carried out in three conference rooms described in Table 1 with different dimensions and different density of people. The building is located in Poland in temperate climates (A humid continental climate is marked by variable weather patterns and a large seasonal temperature variance. Places with more than three months of average daily temperatures above $10^{\circ} \mathrm{C}$ and a coldest month temperature below $-3^{\circ} \mathrm{C}$ ) [24].

Measurements were carried out in January, with external temperatures between $+1{ }^{\circ} \mathrm{C}$ to $-11^{\circ} \mathrm{C}$. This change in the outside temperature took place within 7 days.

Table 1. Parameters of the analysed conference rooms.

\begin{tabular}{|c|c|c|c|c|}
\hline Parameter & Unit & Room 1 & Room 2 & Room 3 \\
\hline area & $\mathrm{m}^{2}$ & 212.2 & 212.6 & 308.82 \\
\hline cubature & $\mathrm{m}^{3}$ & 636.6 & 637.8 & 926.46 \\
\hline number of people & - & 23 & 14 & 55 \\
\hline density of people & $\mathrm{pcs} / \mathrm{m}^{2}$ & 9.23 & 15.19 & 5.61 \\
\hline ventilation system & - & $\mathrm{AC}$ & $\begin{array}{c}\text { mechanical } \\
\text { ventilation }\end{array}$ & $\mathrm{AC}$ \\
\hline multiplicity of exchange & $\mathrm{m}^{3} / \mathrm{h}$ & 2 & 1.7 & 2,1 \\
\hline
\end{tabular}

The buildings in which the rooms are analysed have the same construction and they were built using the same technology over two years.

In the analysed rooms the time of immobility (interest in lectures, without leaving the room) lasted from 60 to 100 minutes. The charts show the common interval that was analysed. 
In all halls there was mechanical ventilation, but in Rooms 1 and 3 there was a possibility of cooling the air - AC. During the measurements, there was no need to cool the air. In all analysed conference rooms, the HVAC system is equipped with temperature regulators (Fig. 1).
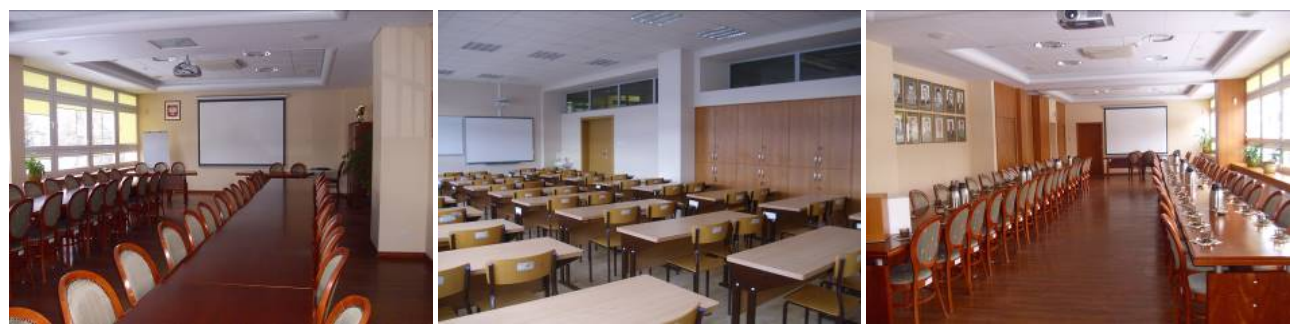

Fig. 1. The analysed rooms 1, 2, 3.

The measurements were made with the Testo 435 recorder with the IAQ probe, whose parameters have been described in publications $[25,26]$. Each point on the graph is the average of 5 measurements in different places in the room. All meters were placed at a height of $1.1 \mathrm{~m}$ from the floor. It was assumed that at this height there is a human head during the deliberations in the conference room. The room is flat, in front there is a slight elevation for the speaker - in this part no measurements were made, because there is a much smaller density of listeners.

\section{Results}

Fig. 2 presents the distribution of humidity in the analysed rooms along with equations approximating the results of humidity measurements and the R2 coefficient - the determination coefficient.

In addition, error bars have been marked in all measurement series.

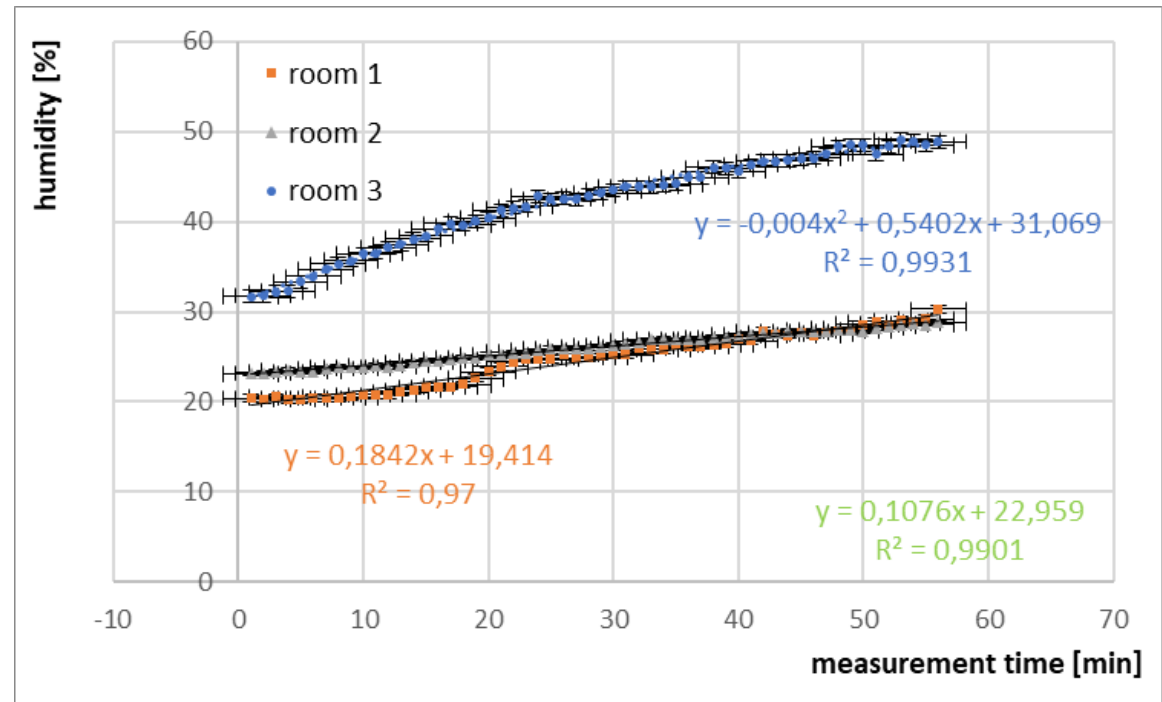

Fig. 2. Distribution of humidity in the analysed rooms. 
The value of humidity during the experiment increased in all analysed rooms by $9.9 \%$ in Hall 1, by $6.4 \%$ - in Room 2, by $24.5 \%$ in Room 3. The error account was carried out in accordance with the recommendations contained in publications $[27,28]$.

The results of humidity measurements were approximated by a straight line. In all the cases analysed, the coefficient of determination showed a very good match (Figure 2).

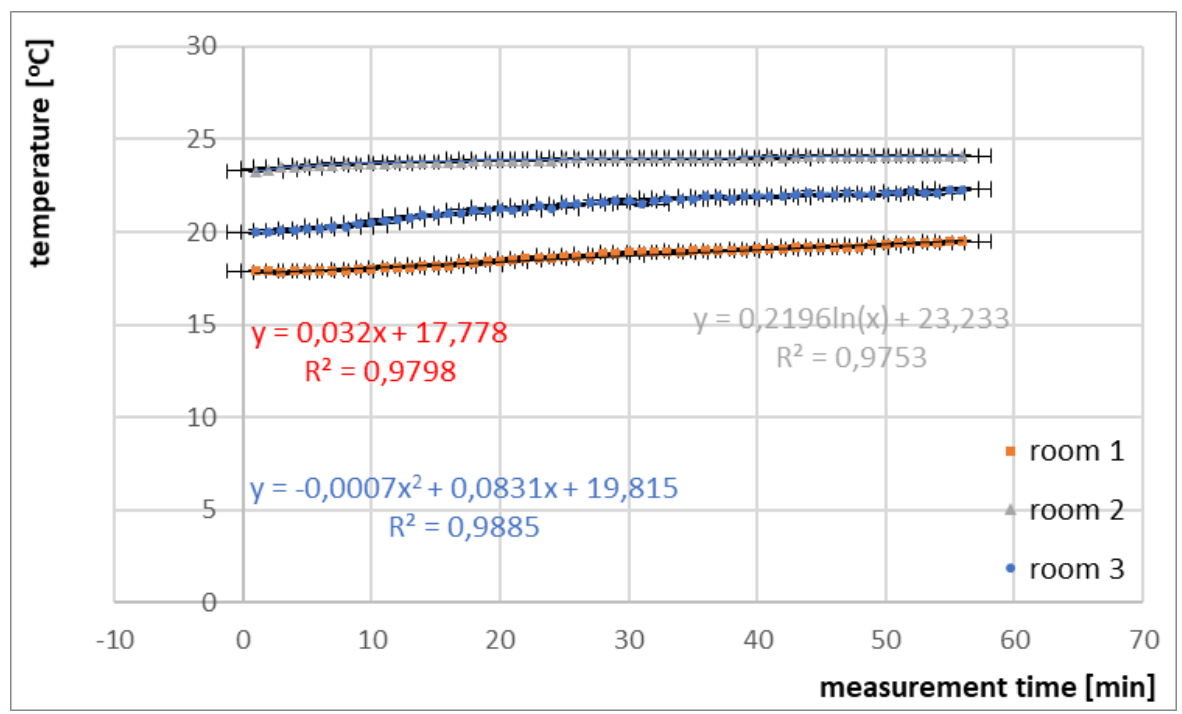

Fig. 3. Temperature distribution in the analysed rooms.

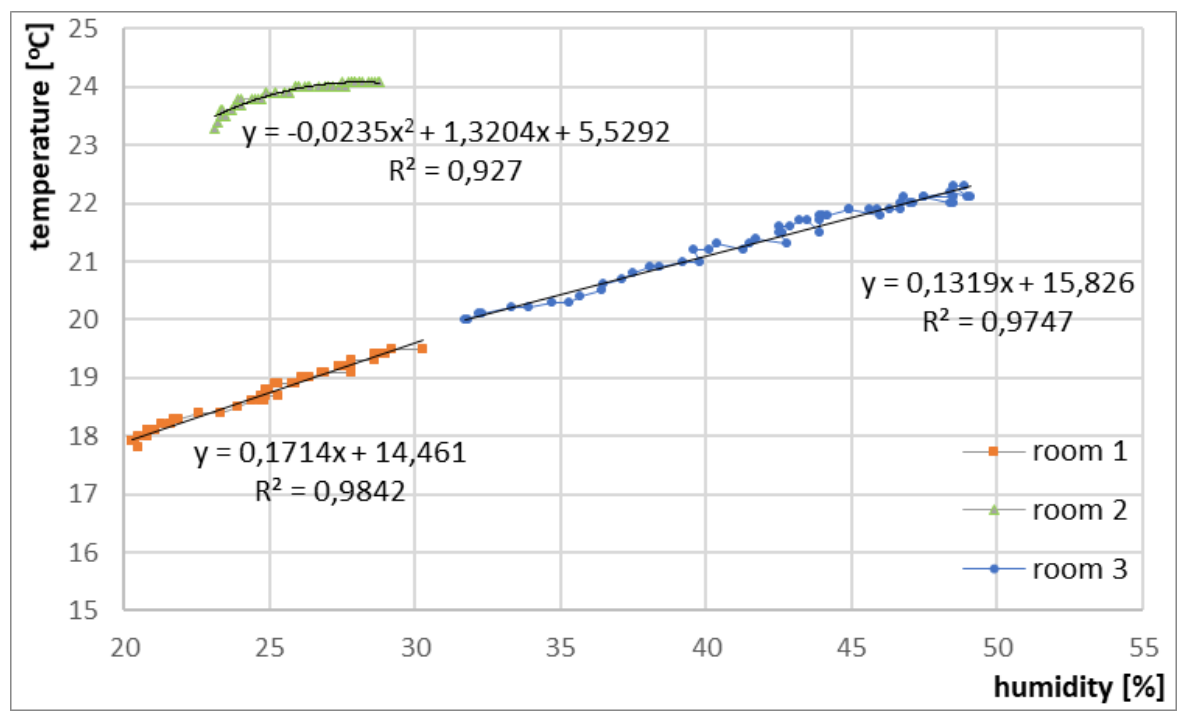

Fig. 4. The correlation of temperature and humidity in the analysed rooms.

Fig. 3 shows the temperature distribution in the analysed rooms. As before, equations approximating the results of temperature measurements and $\mathrm{R}^{2}$ coefficient were given, and error bars in all measurement series were marked. The error account was carried out in accordance with the recommendations contained in publications [27, 28].

The results of temperature measurements in rooms 1 and 3 were approximated by the second-order polynomial, while in room 2 - by the straight line (Figure 3 ). The change in 
the type of the approximation equation was caused by the desire to obtain the results of the very good match model. In room 2, by approximating the results of temperature measurements with a straight line, a good match of 0.83 was obtained. Room 2 is a room with the smallest density of people and the biggest influence on the air temperature in the HVAC room. Despite the temperature regulation - all rooms had a temperature increase in the range of 0.9 to $2.6^{\circ} \mathrm{C}$, in room 2 the increase was the smallest - by $0.9^{\circ} \mathrm{C}$, in room 1 the temperature increased by $1.6^{\circ} \mathrm{C}$, and in room 3 the temperature increased by $2.6^{\circ} \mathrm{C}$. It was concluded that the increase in temperature depends on the number of people in the room.

Observing Fig. 4, the results of approximation of humidity and temperature correlation it must be said, that in rooms 1 and 3 , the determination coefficient shows a very good fit when approximating the results of straight line measurements. In Room 2, when approximating the correlation with a straight line, the coefficient of determination was 0.84 and showed a good fit. Room 2 is the room with the smallest density of people and the largest influence of the HVAC system on correlation.

\section{Discussion}

Man is a correlated entity [8], so the temperature change in the room should be correlated with the humidity. However, the HVAC system disturbs this correlation, which was proved by the measurement results and their analysis (Figures 2-4). However, these disorders, in rooms with a high density of people above 1 person per $10 \mathrm{~m}^{2}$, are below $10 \%$. In a room with a smaller density of people, the correlation disorders amount to almost $20 \%$. In such rooms, the HVAC system has a large impact on the discrepancy, the heating system [29-32]. However, the authors [9] stated that the heating system does not affect the humidity in the room. Small deviations were probably not considered.

The temperature guidelines are followed, HV installations are calculated mainly on this parameter, HVAC installation is also controlled only with this parameter (although there are installations controlled by carbon dioxide concentration, however, they have the task of maintaining the appropriate temperature). The value of humidity is very rarely a measured and controllable value $[3,8,33]$. Two rooms equipped with $\mathrm{AC}$ had a better correlated humidity with temperature than a room equipped with mechanical ventilation without the possibility of cooling the air. In room 2 there was the smallest density of people.

The internal environment during the experiment - in the winter - just like New York City is dry [9]. The exception is the room with a large number of people. The highest density of people caused an increase in humidity in an hour by almost $100 \%$.

The conducted experiment caused more questions than it gave answers. According to the title, these are preliminary studies. Further research should be carried out by checking, in which the density range of people in the room will increase the humidity, in what range of density or number of people the humidity will be correlated with the temperature and whether this correlation is influenced by external conditions or a variable temperature range.

It is necessary to consider the technical possibilities to improve the indoor air quality and humidity. The wide use (currently used in a narrow range) of humidifiers in both public and residential buildings should be examined. 


\section{Conclusion}

In two rooms, the humidity is definitely too low. The HVAC system slightly disrupts the correlation of temperature and humidity.

The number of people in the room affects the amount of humidity increase and despite the use of temperature controllers in the HVAC system, an increase in temperature was observed.

There is no legislation on compliance with guidelines on humidity in the rooms in which people are staying.

Future studies are needed to determine the methodology for measuring public spaces and calculating the humidity and gap indication in national and European standards regarding control humidity requirements.

Acknowledgment - The study has been executed with resources of the S/WBiIŚ/4/14 statutory work financed by the Ministry of Science and Higher Education in Poland and Project co-financed by the European Regional Development Fund under the Regional Operational Program of the Podlaskie Voivodship for the years 2007-2013-5.2 and 1.1.

\section{References}

1. S. Jia, D. Lai, J. Kang, J. Li, J. Liu, Build. Environ. 131, 108-116 (2018)

2. D. A. Krawczyk, Energy Procedia 95, 216-222 (2016). DOI: 10.1016/j.egypro.2016.09.053

3. P. Nejat, F. Jomehzadeh, M. Mahdi Taheri, M. Gohari, M. Zaimi Abd Majid, Renew. Sustain. Energy Rev. 43, 843-862 (2015)

4. M. Chludzinska, A. Bogdan, Build. Environ. 126, 373-381 (2017). DOI: 10.1016/j.buildenv.2017.10.018

5. M. Laska, E3S Web Conf. 17, 8 (2017). DOI https://doi.org/10.1051/e3sconf/20171700050.

6. G. Majewski, M. Telejko, Ł.J. Orman, E3S Web Conf. 17, 7 (2017). DOI https://doi.org/10.1051/e3sconf/20171700056

7. T. Pietrucha, E3S Web Conf. 17, 7 (2017). DOI https://doi.org/10.1051/e3sconf/20171700073

8. M. Vellei, M. Herrera, D. Fosas, S. Natarajan, Build. Environ. 124, 171-185 (2017).

9. A. Quinn, J. Shaman, Sci. Total Environ. 583, 29-35 (2017)

10. A.I. Barreca, J.P. Shimshack, Am. J. Epidemiol. 176, 114-122 (2012)

11. T. H. Koep, F. T. Enders, C. Pierret, S. C. Ekker, D. Krageschmidt, K. L. Neff, M. Lipsitch, J. Shaman, W. Ch. Huskins, BMC Infect. Dis. 13, 1-8 (2013)

12. J.D. Noti, F.M. Blachere, C.M. McMillen, W.G. Lindsley, M.L. Kashon, D.R. Slaughter, D.H. Beezhold, PLoS ONE8(2): e57485, (2013). https://doi.org/10.1371/journal.pone.0057485.

13. D.R. Lide, CRC Handbook of Chemistry and Physics (90 ed.). CRC Press. ISBN 9781420090840, 17-27 (2009)

14. R.H. Perry, D.W. Green, Perry's Chemical Engineers' Handbook (8th Edition), McGraw-Hill, ISBN: 9780071422949 , Eqn 12-7 (2008)

15. Ch. Li, H. Liu, B. Li, Y. Cheng, Ch. Du, A. Sheng, Build. Environ. 123, 458-468 (2017)

16. L. Jin, Y. Zhang, Z. Zhang, Build. Environ. 114, 257-266 (2017)

17. Y. Li, Y. Yuan, Ch. Li, X. Han, X. Zhang, Build. Environ. 131, 53-62 (2018) 
18. E. Brągoszewska, J.S. Pastuszka, J. S. Aerobiologia, 1-15 (2018) https://doi.org/10.1007/s10453-018-9510-1

19. Y. Zhang, G. Feng, Z. Kang, Y. Bi, Y. Cai, Procedia Eng. 205, 302-308 (2017)

20. R. Cichowicz, E3S Web Conf. 22, 8 (2017). DOI https://doi.org/10.1051/e3sconf/20172200030

21. American Society of Heating, Refrigerating and Air-Conditioning Engineers Guidelines for Design and Constructions of Health Care Facilities (2006)

22. EN 13779, Ventilation of residential buildings. Requirements for the properties of ventilation and air conditioning (2008)

23. World Health Organization. Indoor Environment: Health Aspects of Air Quality, Thermal Environment, Light and Noise (1990)

24. M.C. Peel, B.L. Finlayson, T.A. McMahon, Hydrol. Earth Syst. Sci. 11(5), 1633-1644 (2007). doi:10.5194/hess-11-1633-2007

25. K. Gładyszewska-Fiedoruk, Transport. Res. Part D: Transp. Environ. 16(4), 327-331 (2011)

26. K. Gładyszewska-Fiedoruk, M. Nieciecki, Energy Procedia 95, 132-139 (2016)

27. M.J. Sulewska, Balt. J. Road Bridge E. 7(1), 36-41 (2012)

28. M.J. Sulewska, Pol. J. Environ. Stud. 19(4), 797-804 (2010)

29. K. Palaszynska, K. Bandurski, M. Porowski, E3S Web Conf. 22, UNSP 00130 (2017)

30. A. Szczurek, M. Maciejewska, M. Uchronski, E3S Web of Conf. 22, UNSP 00172 (2017).

31. D. A. Krawczyk, P. Zielinko, A. Rodero, W trakcie druku. 2018. IOP Conference Series: Earth and Environmental Science (EES)

32. B. Zawada, J. Build. Phys. 40(4), 346-371 (2017)

33. X. Song, L. Yanga, W. Zhenga, Y. Rena, Y. Lin, Procedia Eng. 121, 151-157 (2015) 